\title{
Review of: "The earliest Pleistocene record of a large- bodied hominin from the Levant supports two out-of- Africa dispersal events"
}

Lior Weissbrod

Potential competing interests: The author(s) declared that no potential competing interests exist.

The connection between hominin biological and techno-cultural development, and the fundamental idea that stone industries provide a most important tracer of human evolution, remain a matter of heated debate in prehistoric research and paleoanthropology. The reviewed study by Barash et al. suggests an independent out-of-Africa dispersal event at 1.6-1.2 Ma by large-bodied hominins and the makers of Acheulian technology, documented at the Levantine site of 'Ubeidiya. This event may have superseded the expansion of small-bodied hominins with Oldowan stone industries, as attested at the $1.8 \mathrm{Ma}$ site of Dmanisi in the Caucasus. This separate dispersal event moreover appears to have taken place in the context of a different global climate, likely resulting in novel challenges to dispersing hominins. Based on their analysis of a complete lower lumbar vertebral body, the authors cautiously assign this specimen (UB 10749) to the African group of Homo erectus-affiliated populations. While the author of this brief review is unqualified to discuss the present find in more detail than the study's authors, the importance of this find and its implications for current research in human evolution are quite clear. The reviewed study is an avid reminder of the centrality and significance of the Levantine corridor to research on human evolution, a region which continues to yield surprising paleoanthropological findings even after nearly a century of investigations. 